\title{
External Recruitment as an Incentive
}

\section{Device}

\author{
Kong-Ping Chen* \\ Institute for Social Sciences and Philosophy \\ Academia Sinica \\ Taipei, 11529, Taiwan \\ kongpin@gate.sinica.edu.tw
}

November 5, 2003

\begin{abstract}
External recruitment has often been viewed as a necessary evil in that it trades off the need for outside talents with the incentives of inside workers. This paper, however, shows that even from an incentive viewpoint, external recruitment has its positive role to play. Specifically, if promotion is based on relative performance, then negative activities in the form of sabotage are a valuable instrument to compete. This results in inefficiency of the workers' efforts and performance of the firm. External recruitment, by reducing the marginal return of negative activity relative to that of productive activity, can restore the incentives of the workers to engage in productive activity and enhances the firm's performance. We also show that even when negative activities are not a concern, external recruitment can sometimes avoid the shirking equilibrium, or prevents collusion of the workers.
\end{abstract}

*I thank Ji-Shyan Wang for initial collaboration, and participants of the 2002 Annual Congress of European Economic Association in Venice for comments. Financial support from Hong Kong University of Science and Technology (DAG\\#99/00.BM49) and Taiwan's National Science Council (89-2415-H001-042) are gratefully acknowledged. 


\section{Introduction}

Economists have long emphasized the importance of the internal labor market in shielding workers from external labor market fluctuations. ${ }^{1}$ The internal labor market is supposed to function in a way that, except for the designated "port of entry", open positions should be filled by internal promotion. This characterization, however, is contradictory to recent evidence. For example, Baker et al. (1994) show that, within the firm they study, there is substantial entry in all levels of job. ${ }^{2}$ Furthermore, the importance of external recruitment seems to have increased in the past few decades. ${ }^{3}$ Kanter (1989) also observes that "climbing career ladder is being replaced by hopping from job to job." Given the prevalence of external recruitment and the important role it gradually plays, it is essential to understand its implied impact on workers' incentives. An obvious reason to recruit externally instead of promoting from within is that the outsiders might possess specific skills or characteristics that the firm needs. (Baron and Kreps, 1999.) That is, the main reason for a firm to recruit externally is not to provide incentives for the workers. If anything, it decreases the promotion chance of the inside workers and thus adversely affects the incentive of insiders to work. ${ }^{4}$ In other words, it exacerbates the moral hazard problem within a firm. Even without this moral hazard consideration, recruited outsiders often lack the firm-specific investment that the insiders have built up through their careers within the firm. External recruitment is thus a necessary evil in that it trades off the need for outside talents with insider workers' incentives.

The purpose of the paper is to show that, contrary to the opinion in the previous

\footnotetext{
${ }^{1}$ See, for example, the classic treatment in Doeringer and Piore (1985).

${ }^{2}$ They find that over 25 percent of workers entering levels 2-4 (on an 8-level ladder) of the firm are hired from the outside.

${ }^{3}$ For example, Osterman (1999, p.44) refers to a research project by A. Bernhardt, M. Morris, M. Handcock and M. Scott reported to the Russell Sage and Rockefeller Foundations showing that there is substantial increase in job turnover from a cohort of young men entering the labor force in 1966-1981, to another cohort in years 1979-1984. If different cohorts in the sample work for the same span of years in lifetime, then there must be increase in external recruitment in the same period. A study of careers of managers in telecommunication service by Batt (1996) also documents a greater use of external recruitment for middle and upper management positions.

${ }^{4}$ See, for example, Lazear (1995) and Chan (1996).
} 
literature, even if viewed from an incentive perspective, external recruitment also has its positive function. In most of the firms, promotion is based on relative, rather than absolute, performance. ${ }^{5}$ In other words, competition for promotion is a tournament in the sense that, what matters for the workers is not how well they perform, but whether they outperform others in the same firm. ${ }^{6}$ Furthermore, in this rank-order tournament, the winner takes all the prize. Given these natures of promotion tournament, it is not surprising that workers competing for promotion will eventually engage in "sabotages", the disruptive behaviors whose main function is only to undercut opponents' performance. ${ }^{7}$ The consequence of this behavior is not only that the workers waste resources in unproductive activities, but also that those who have greatest chance to win the promotion tournament are not necessarily of the highest caliber. ${ }^{8}$

By recruiting externally, the firm decreases not only the chance of promotion (and thus the marginal returns of productive activities as mentioned in previous literature), but also the effectiveness of negative activities. The latter has two effects on the workers' incentives. First, as in the case for productive activities, since external competition reduces the marginal return of negative activities, the level of negative activities will decrease. The second, and perhaps more important, effect is that while sabotage is almost useless in competing against outsiders, productive effort remains a useful instrument. The workers will thus substitute productive for negative effort, which results in an increase in productive effort and a further reduction of negative activity. We show that although the total effort of the workers will decrease, this is in fact the net outcome of a reduction of sabotage and an increase of productive activity. In a word, although external recruitment hurts the "morale" of insiders by reducing their chance to be promoted, the outputs of

\footnotetext{
${ }^{5}$ DeVaro (2002) provides evidence showing that it is relative, rather than absolute, performance that strongly influences chance of promotion.

${ }^{6}$ Green and Stokey (1983), Lazear and Rosen (1981) and Rosen (1986) are seminal works on tournaments. Hvide (2002) and Zabojnik and Bernhardt (2001) are recent theoretical papers, and Bognanno (1999) and Eriksson (1999) recent empirical works.

${ }^{7}$ See Lazear (1989) for the seminal work on sabotage in a firm, and Chen (2003) for its consequence on the workers' incentives and promotion prospects.

${ }^{8}$ See Chen (2003).
} 
the workers actually increase. ${ }^{9}$

The incentive effect mentioned above is in fact much more general than in the context when sabotage is a concern. For example, suppose there are two workers, each having a binary choice of whether to work hard or to shirk. Further assume that no sabotage is possible in the firm. If there is no external recruitment, then the promotion chance is $1 / 2$ in both the cases when they all work hard and when they all shirk. That is, they suffer no loss in promotion chance when both shirk. If the disutility of working is substantially higher than to shirk, then shirking is the unique equilibrium outcome. This, however, is no longer true with external competition. Since the inside workers are also competing with outsiders, their promotion probability is lower when they both shirk than when they both work hard. If the difference in promotion chances is large enough, then the unique equilibrium becomes the one in which both work hard.

Another possibility is that although it is an equilibrium for the workers to work hard, they might actually face a Prisoner's Dilemma in the sense that the utility of both workers can improve if they can credibly collude to shirk. We will show that even if this is possible, external recruitment can sometimes reduce their promotion chance by so much that it is not even profitable to collude. The reason for this is exactly the same: When they both shirk, no matter by coordination or by collusion, they only give freeride to outside competitors. We thus show that external recruitment not only has the function of reducing sabotage, but also has the power to change the payoff structure of the promotion tournament game in a way that it breaks shirking as either an equilibrium or a collusive outcome. ${ }^{10}$

The remainder of the paper is organized as follows. Section 2 presents the model.

\footnotetext{
${ }^{9}$ Other works that discuss recruitment from a strategic viewpoint are Chan (1996) and Friebel and Raith (2001). The first paper shows that external recruitment has negative impacts on the workers' incentives, so an outsider should be given a hurdle, and perform substantially better than insiders in order to be recruited. The second paper argues that in order to provide middle-level managers incentives to recruit high quality subordinates, there should be restricted channels of communication in a hierarchy.

${ }^{10}$ A recent paper by Müller and Wärneryd (2001) has shown that introducing outside ownership has the effect of reducing rent-seeking conflict of members in a production team. The intuition of their result is the same as here: External competition reduces the prize of winning, and thus marginal return rent-seeking behavior.
} 
Section 3 discusses the role of external recruitment in shaping the incentives of inside workers, and shows that it can unconditionally improve the performance of a firm. Section 4 discusses other incentive effects of external recruitment when sabotage is not a concern. Section 5 concludes.

\section{The Model}

There are $n$ workers in a firm, and one of them will be promoted to a higher rank. The criterion for promotion is based on performance, which is a function of the workers' effort levels and abilities. Since we are mainly interested in the workers' incentives in effort, it is assumed that all workers have the same ability. The performance of a worker increases with both effort and ability. A simple formulation capturing this idea is to assume that the performance of worker $i$ is $t e_{i}+\varepsilon_{i}$, where $e_{i}$ is effort level of worker $i$, and $t$ is the ability of the workers. Assume that $\varepsilon_{i}$ and $\varepsilon_{j}$ are IID, and $f(\cdot)$ is the density function for $\varepsilon_{i}, i=1, \ldots, n$, which is single-peaked on, and symmetric around, 0 so that $E\left(\varepsilon_{i}\right)=0$. $\varepsilon_{i}$ can be interpreted as luck of a worker. Our assumption implies that luck is "fair". Let $W_{i}=t e_{i}$ be the expected performance of worker $i .^{11}$ The disutility of effort for worker $i$ is $v\left(e_{i}\right)$, with $v^{\prime}>0, v(0)=0$, and $v^{\prime \prime}>0$. The utility of promotion is $u>0$ for every worker, and is 0 if a worker is not promoted. $u$ can thus be interpreted as wage gap between ranks. The expected utility of worker $i$ is assumed to be $u\left(e_{i}\right)=\operatorname{Prob}(i$ is promoted $u-v\left(e_{i}\right),{ }^{12}$ and we further assume that the worker with the highest value of performance is promoted. In this case we can rewrite $u\left(e_{i}\right)$ as

$$
\begin{aligned}
u\left(e_{i}\right) & =\operatorname{Prob}\left(W_{i}+\varepsilon_{i} \geq W_{j}+\varepsilon_{j} \quad \forall j\right) u-v\left(e_{i}\right) \\
& =u \int_{-\infty}^{\infty} \Pi_{j \neq i} F\left(W_{i j}+\varepsilon_{i}\right) f\left(\varepsilon_{i}\right) d \varepsilon_{i}-v\left(e_{i}\right),
\end{aligned}
$$

\footnotetext{
${ }^{11}$ We will also call $W_{i}$ the expected output of worker $i$.

${ }^{12}$ In order to emphasize the rank-order tournament nature of promotion, we have assumed that the incentive to work is provided solely by the prospect of promotion. In general, there are other ways to reward effort, the most obvious one being the incentive payment where, say, a propotion of output is given to the workers. Incorporating these payments will not change the main results of the paper.
} 
where $F(\cdot)$ is the distribution function of $f(\cdot)$ and $W_{i j}=W_{i}-W_{j}$ is the difference in expected performance between $j$ and $i$. Every worker $i$ chooses the value of effort level $e_{i}$ to maximize his own expected utility. This is a game played among the $n$ workers, and the symmetric Nash equilibrium is characterized by

$$
(n-1) u t \int_{-\infty}^{\infty} f(\varepsilon)^{2} F(\varepsilon)^{n-2} d \varepsilon=v^{\prime}(e)
$$

It can be easily seen that the equilibrium effort level $e^{*}$ rises with the utility of promotion $u$ and ability $t$. Let $W^{*}$ be the expected equilibrium performance of a worker, i.e., $W^{*} \equiv t e^{*}$

The workers, however, can also engage in "negative" activities, and "sabotage" other workers in order to destroy their performance (Lazear, 1989; Chen, 2003). Negative activities are worthwhile because promotion is based on relative, rather than absolute, performance. Suppose $a_{i j}$ is the level of "sabotage" worker $i$ exerts against $j$, and that the expected performance of member $i$ is $W_{i}=t e_{i}-g\left(\sum_{j \neq i} a_{j i}\right)$; where $g^{\prime}>0, g^{\prime \prime}<0$, and $g(0)=0$. The function $g$ measures the effectiveness of negative effort in destroying the opponent's performance. It is a function of the sum of the levels of all other workers' attack against $i$, meaning that there is no "synergy" in joining negative efforts. The disutility of effort for worker $i$ is assumed to be $v\left(e_{i}+\sum_{j \neq i} a_{i j}\right)$, meaning that positive and negative efforts are "equally undesirable". Worker $i$ chooses the levels of $e_{i}$ and $a_{i j}(j \neq i)$ to maximize expected utility

$$
u\left(e_{i}, a_{i}\right)=\operatorname{Prob}\left(W_{i}+\varepsilon_{i} \geq W_{j}+\varepsilon_{j} \quad \forall j\right) u-v\left(e_{i}+\sum_{j \neq i} a_{i j}\right)
$$

where $a_{i} \equiv\left(a_{i 1}, a_{i 2}, \ldots, a_{i j-1}, a_{i j+1}, \ldots, a_{i n}\right)$. We will consider the case when both $e_{i}$ and $a_{i}$ are strictly positive, so that the symmetric Nash equilibrium is characterized by firstorder conditions

$$
\begin{gathered}
(n-1) u t \int_{-\infty}^{\infty} f(\varepsilon)^{2} F(\varepsilon)^{n-2} d \varepsilon=v^{\prime}\left(e^{* *}+(n-1) a^{* *}\right), \\
u g^{\prime}\left((n-1) a^{* *}\right) \int_{-\infty}^{\infty} f(\varepsilon)^{2} F(\varepsilon)^{n-2} d \varepsilon=v^{\prime}\left(e^{* *}+(n-1) a^{* *}\right) .
\end{gathered}
$$


We consider only the meaningful case when $W^{* *} \equiv t e^{* *}-g\left((n-1) a^{* *}\right)>0$. From $(2)$ and (3) we know that $g^{\prime}\left((n-1) a^{* *}\right)=(n-1) t$. It can be easily seen that $a^{* *}$ decreases with both $t$ and $n$. That is, when the ability or number of the workers increases, the level of every worker's disruptive activity decreases. Moreover, $e^{* *}$ is increasing in wage gap $u$. A direct comparison between $(1)$ and $(2)$ shows that $e^{*}=e^{* *}+(n-1) a^{* *}$. As a result, $e^{*}>e^{* *}$, i.e., the workers exert less productive effort, and thus produce lower output when they can engage in negative activities. Obviously, it follows that $W^{* *}<W^{*}$. This result clearly shows that negative activities encroach on the efficiency of a firm: They divert the efforts of the members from productive to disruptive ones. Not only that, part of a member's performance is destroyed by others' negative effort.

Now suppose that the firm can search for talents from the outside to fill the higher position. This can be done in two ways. The first is to locate an outsider with proven performance $\bar{W}$. The firm will promote an inside top performer only if his performer is higher than $\bar{W}$; otherwise this outsider is recruited. Alternatively, the firm can set a threshold of performance $\bar{W}$. An insider is considered for promotion only if his performance is greater than $\bar{W}$; otherwise it commits to search for an outsider to fill the position. Technically these two practices are equivalent. ${ }^{13}$ In either case, the expected utility of worker $i$ is

$$
u\left(e_{i}, a_{i}\right)=\operatorname{Prob}\left(W_{i}+\varepsilon_{i} \geq W_{j}+\varepsilon_{j} \quad \forall j, \text { and } W_{i}+\varepsilon_{i} \geq \bar{W}\right) u-v\left(e_{i}+\sum_{j \neq i} a_{i j}\right) .
$$

Implicit in this formulation is the assumption that the workers cannot sabotage an outsider. It can be justified in several ways. First, the identity of the outsider to be recruited is still unknown at the stage of competition. This is especially true if we adopt the performance threshold interpretation of external recruitment. In this case it is simply impossible to attack the potential opponents. Second, even if the identity is known, because of geographic or informational reasons, it is much more difficult to sabotage an outsider than an insider. Our qualitative results hold true if instead we assume that it is

\footnotetext{
${ }^{13}$ For expositional ease we will adopt the second practice in the main body of the paper. The interpretation for Theorem 1, however, are different for the two practices.
} 
also possible to attack an outsider, but its effectiveness is sufficiently lower than that for the insiders. As a result of our assumption, the only way to compete with an outsider is through higher level of productive effort $e_{i}$.

Worker $i$ 's chance of promotion can be re-written as $\int_{W-W_{i}}^{\infty} \prod_{j \neq i} F\left(W_{i j}+\varepsilon_{i}\right) f\left(\varepsilon_{i}\right) d \varepsilon_{i}$, and the symmetric Nash equilibrium is characterized by

$$
\begin{gathered}
u t\left\{f(\bar{W}-W) F(\bar{W}-W)^{n-1}+(n-1) \int_{\bar{W}-W}^{\infty} f(\varepsilon)^{2} F(\varepsilon)^{n-2} d \varepsilon\right\}=v^{\prime}(e+(n-1) a), \\
u g^{\prime}((n-1) a) \int_{\bar{W}-W}^{\infty} f(\varepsilon)^{2} F(\varepsilon)^{n-2} d \varepsilon=v^{\prime}(e+(n-1) a) ;
\end{gathered}
$$

where $W$ is the common value of $W_{i}(i=1, \ldots n)$. Denote the solutions of (4) and (5) by $e^{E}$ and $a^{E}$, and define $W^{E}=t e^{E}-g\left((n-1) a^{E}\right)$ as the equilibrium expected performance of a worker. Again, for all the discussion in the following we will assume that (4) and (5) characterize the equilibrium. From (4) and (5) we can show that

$$
u t(n-1) \int_{\bar{W}-W^{E}}^{\infty} f(\varepsilon)^{2} F(\varepsilon)^{n-2} d \varepsilon<u g^{\prime}\left((n-1) a^{E}\right) \int_{\bar{W}-W^{E}}^{\infty} f(\varepsilon)^{2} F(\varepsilon)^{n-2} d \varepsilon .
$$

By the fact that $g^{\prime}\left((n-1) a^{* *}\right)=(n-1) t$ we have $(n-1) t<g^{\prime}\left((n-1) a^{E}\right)$. This implies that $a^{E}<a^{* *}$ : With external recruitment, the workers will engage in less disruptive activities. The reason behind this result is quite intuitive. External recruitment increases the number of workers competing for promotion, and thus reduces the marginal return of negative activities. The inside workers will therefore respond with less negative activities.

The level of productive effort, however, does not necessarily decrease. As external recruitment is introduced, there are two forces that influence the level of productive effort. On the one hand, productive effort is reduced in response to its lower marginal return. This is exactly the same reason behind the reduction in sabotage. We called this an "income effect". On the other hand, since productive effort remains useful in competing with outsiders while sabotage does not, the extent of reduction in marginal return is greater for negative than for productive effort. The "substitution effect" will thus force workers to substitute productive for negative effort. The change in productive effort will therefore depend on the relative strength of the above two forces. 
As to its impact on the total effort $e+(n-1) a$, rewrite the left-hand-side of $(2)$ as

$$
\begin{aligned}
& (n-1) u t \int_{-\infty}^{\bar{W}-W^{E}} f(\varepsilon)^{2} F(\varepsilon)^{n-2} d \varepsilon+(n-1) u t \int_{\bar{W}-W^{E}}^{\infty} f(\varepsilon)^{2} F(\varepsilon)^{n-2} d \varepsilon \\
= & u t f\left(\bar{W}-W^{E}\right) F\left(\bar{W}-W^{E}\right)^{n-1} \\
& -u t \int_{-\infty}^{\bar{W}-W^{E}} f^{\prime}(\varepsilon) F(\varepsilon)^{n-1} d \varepsilon+(n-1) u t \int_{\bar{W}-W^{E}}^{\infty} f(\varepsilon)^{2} F(\varepsilon)^{n-2} d \varepsilon .
\end{aligned}
$$

Comparing (6) with the left-hand-side of (4), we can see that the term $-u t \int_{-\infty}^{\bar{W}-W^{E}}$ $f^{\prime}(\varepsilon) F(\varepsilon)^{n-1} d \varepsilon$ is the difference in marginal return of productive effort between the cases with and without external recruitment. Depending on the value of $\bar{W}$ and the function $f(\cdot)$ itself, this term can be either positive or negative. Since $f^{\prime}(x)>0$ for all $x<0$, we know this term is negative if $\bar{W} \leqslant W^{E}$, which in turn implies that $e^{E}+(n+1) a^{E}<$ $e^{* *}+(n+1) a^{* *}:$ The total effort is smaller under external recruitment if the performance threshold $\bar{W}$ is chosen to be smaller than the expected total performance of insiders. We summarize our results in Proposition 1.

Proposition 1 With external recruitment, every worker will engage in less negative activity. Moreover, when the performance threshold $\bar{W}$ is not greater than the expected performance of the inside workers, the workers exert less total effort.

Since promotion chance is at most 1 , the expected utility of a worker is bounded above by $u$. Moreover, since both $a^{E}$ and $e^{E}$ can take only non-negative values and since $v^{\prime \prime}>0, a^{E}$ and $e^{E}$ must also be bounded. $\bar{W}-W^{E}$ thus approaches infinity, and the left-hand-side of (5) approaches 0 , when $\bar{W} \rightarrow \infty$. Therefore, there exists $\underline{W}$ such that $a^{E}=0$ for $\bar{W} \geqslant \underline{W}$. That is, if the value of $\bar{W}$ is high enough so that promotion is sufficiently difficult, then sabotage disappears. This, however, does not imply that the firm should optimally set a performance threshold high enough to eradicate sabotage. The reason is that a high performance threshold also implies low productive effort $e$. As a result, it might not be optimal for a firm to choose a $\bar{W}$ that can eliminate sabotage, because it might at the same time induce very low productive effort. In the next section we set out to find the optimal value of $\bar{W}$ that maximizes the firm's output. 


\section{The Optimal External Recruitment Policy}

In this section we investigate the role of external competition in shaping the workers' incentives in (both productive and negative) efforts. We then derive the optimal performance threshold $(\bar{W})$ and wage gap $(u)$ of the firm and the optimal recruitment and wage policies they imply. To emphasize the dependence of $a^{E}, e^{E}$ and $W^{E}$ on the performance threshold $\bar{W}$, we will write them as $a^{E}(\bar{W}), e^{E}(\bar{W})$ and $W^{E}(\bar{W})$.

The performance threshold, $\bar{W}$, obviously has a great bearing on the incentives of the workers, and eventually on the output of the firm. For example, as $\bar{W} \rightarrow-\infty$, every insider makes the threshold for sure, and the case is equivalent to when the firm only promotes internally. ${ }^{14}$ That is, $\lim _{W \rightarrow-\infty} e^{E}(\bar{W})=e^{* *}, \lim _{W \rightarrow-\infty} a^{E}(\bar{W})=a^{* *}$ and $\lim _{W \rightarrow-\infty} W^{E}(\bar{W})=W^{* *}$. When $\bar{W} \rightarrow \infty$, the promotion chance of inside workers goes to zero, and the optimal effort levels are thus corner solutions with $e^{E}=a^{E}=0$. Consequently, $\lim _{\bar{W} \rightarrow \infty} W^{E}(\bar{W})=0$. We first investigate the effects of $\bar{W}$ on the workers' effort levels.

Proposition $2 \partial e / \partial \bar{W}>0$ and $\partial a / \partial \bar{W}<0$ if $\bar{W} \leqslant W^{E}(\bar{W})$.

Proof: See the Appendix.

Proposition 2 says that a worker's productive (negative) effort increases (decreases) with the level of performance threshold, if the value of the threshold is not higher than the expected performance of insiders. Since the case when there is no external competition corresponds to when $\bar{W}=-\infty$, which in turn implies effort level $e^{* *}$ and $a^{* *}$, if the firm gradually raises the performance threshold $\bar{W}$ from a very low value, then by Proposition 2 a worker's negative effort will gradually decrease from $a^{* *}$, and productive effort increases from $e^{* *}$. In other words, as long as $\bar{W} \leqslant W^{E}$, the effort levels will be such that $e^{E}(\bar{W})>e^{* *}$ and $a^{E}(\bar{W})<a^{* *}$. Since $W^{E}(-\infty)=W^{* *}>0$, we know that $W^{E}(\bar{W})>W^{* *}$, and is increasing in $\bar{W}$, as long as $\bar{W} \leqslant W^{E}(\bar{W})$. This in turn implies that the value of $\bar{W}$ that maximizes output $W^{E}$ must be such that $W^{E}(\bar{W})>W^{* *}$. The reason for this is quite simple: since $W^{* *}$ is independent of $\bar{W}$, and $W^{E}(\bar{W})$ is increasing

\footnotetext{
${ }^{14}$ This can be easily seen by the fact that when $\bar{W} \rightarrow-\infty,(4)$ reduces to (2) and (5) to (3).
} 
when $\bar{W} \leqslant W^{E}(\bar{W})$, the value of $\bar{W}$ that maximizes $W^{E}(\bar{W})$ cannot possibly be below $W^{E}(\bar{W})$, as the firm can still raise $\bar{W}$ to increase output. We thus have:

Proposition 3 The value of the performance threshold that maximizes $W^{E}(\bar{W}), \bar{W}^{o}$, is such that $W^{E}\left(\bar{W}^{o}\right)>W^{* *}$ and $W^{E}\left(\bar{W}^{o}\right)<\bar{W}^{o}$.

Proof: See Appendix.

The function $W^{E}(\bar{W})$ can thus be depicted as in Figure 1.

The intuition for Proposition 3 is as follows. When the performance threshold is raised, the marginal returns for both productive and negative effort decreases. We call the corresponding reduction in efforts the "income effect". However, there is another force that affects the value of efforts. While sabotage is not useful against outsiders, productive effort remains an useful instrument in competing with the outsiders. The workers will thus substitute productive for negative effort. While this "substitution effect" might not dominate the income effect, it ensures that the reduction in (output-destroying) sabotage is large enough to increase the total output.

Proposition 3 implies that, if we adopt the first interpretation of external recruitment mentioned in Section 2, then outsiders should be given a "hurdle" in competing with inside workers. That is, the firm only considers outsiders whose performance is higher than that expected of the insiders as potential candidates to be recruited. This is consistent with Chan (1996), which proves the same result in the context without sabotage. There are, however, two differences that need to be noted. First, while in Chan (1996) productive effort necessarily decreases when there is external recruitment, in our model it is not necessarily so. In fact, not only productive effort, but also total effort might very well increase. Second, in Chan (1996) external recruitment is an evil that the firm must bear (productive effort decreases), while in our model it actually increases total output at the optimum.

If we adopt the second interpretation of external recruitment, then since $\bar{W}^{o}>$ $W^{E}\left(\bar{W}^{o}\right)$, the inside workers must perform better than expected to be promoted. That is, only ones who perform exceptionally well are to be considered as candidates for pro- 


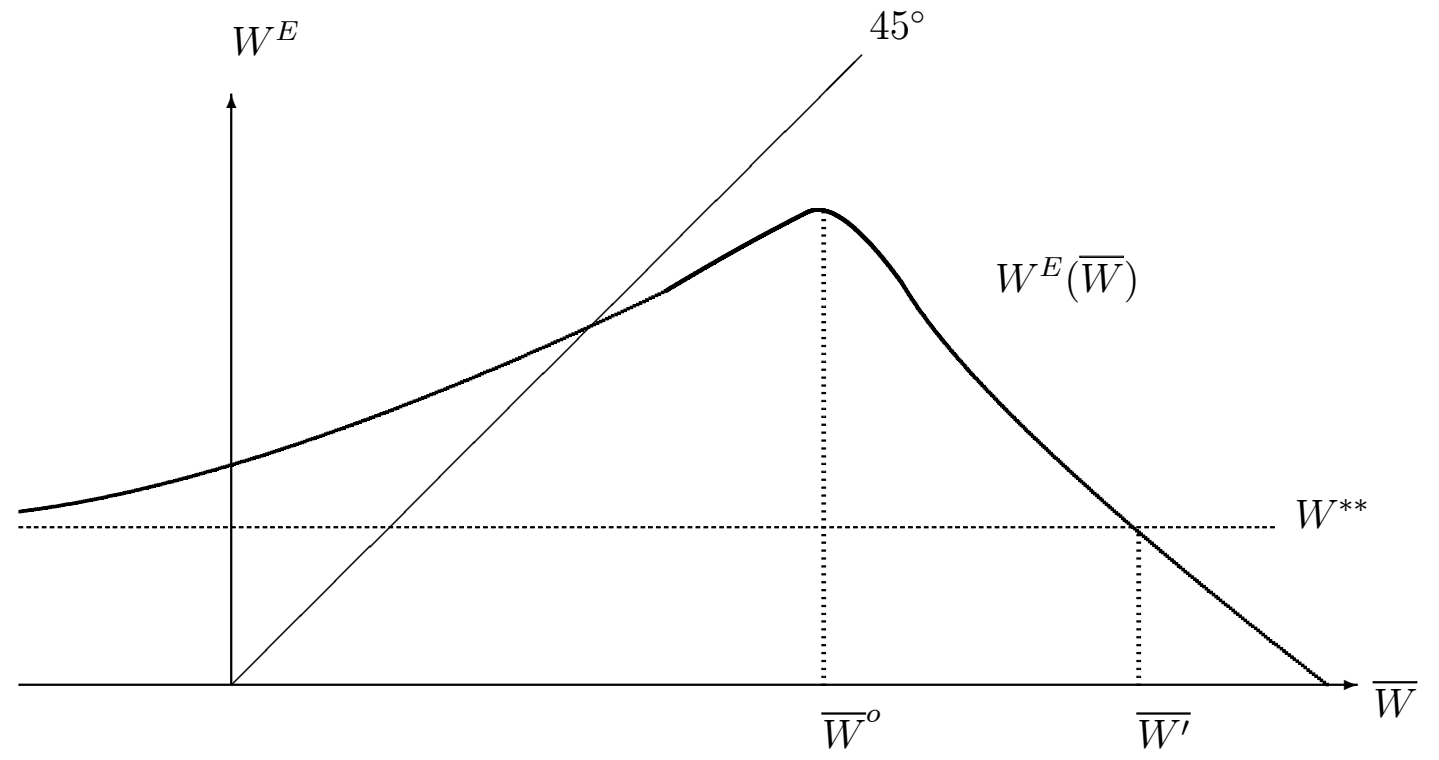

Figure 1 Output as a function of performance threshold 
motion. Note that since we assume that all workers have the same ability, they actually have the same expected performances. As a result, only those who are lucky will make the threshold $\bar{W}^{o}$. In this sense external recruitment is purely used to lessen incentives for sabotage. Put differently, it is purely an incentive device.

Proposition 3 is of great significance in that it fully justifies external recruitment on incentive grounds, for external recruitment ameliorates the problem of infight without reducing incentives toward productive activities. It should be emphasized that in contrast to the traditional literature, in our model external recruitment increases, rather than reduces the productive effort.

It should also be emphasized, however, that despite the result in Proposition 3, the objective of the firm is not to maximize output. This is because in order to increase output, it might be that the worker's total effort, $e+(n-1) a$, has to be increased. (We will show shortly that as $\bar{W}$ increases, total effort $e+(n-1) a$ will indeed increase.) In that case the disutility of effort increases, and the workers need to be paid more in order to raise output. In particular, if the worker is paid a reservation utility that equals the total disutility of effort, then the increase in wage payment might outweigh the increase in output thus produced. In other words, the firm might pay too high a price to maximize output $W^{E}$. Following Lazear and Rosen (1981) and Chan (1996), we will thus assume that the objective of the firm is to maximize the sum of workers' utilities subject to zero-profit constraint:

$$
\begin{aligned}
& \max _{\bar{W}, u} \sum_{i=1}^{n} p_{i}^{E} u-\sum_{i=1}^{n} v_{i}^{E} \\
& \text { s.t. } \quad u=\sum_{i=1}^{n} W_{i}^{E}(\bar{W}) ;
\end{aligned}
$$

where $p_{i}^{E}$ is the promotion probability of worker $i$, and $v_{i}^{E} \equiv v\left(e_{i}^{E}+(n-1) a_{i}^{E}\right)$. Substituting the zero-profit constraint into the objective function, we know that in the symmetric equilibrium the firm maximizes 


$$
\begin{aligned}
& \sum_{i=1}^{n} p_{i}^{E} \sum_{i=1}^{n} W_{i}^{E}(\bar{W})-\sum_{i=1}^{n} v_{i}^{E} \\
= & n\left(n p^{E} W^{E}(\bar{W})-v^{E}\right) \equiv n \pi(\bar{W}, u) .
\end{aligned}
$$

The firm thus chooses $\bar{W}$ and $u$ in order to maximize $\pi(\bar{W}, u)$. Denote the optimal values of $\bar{W}$ and $u$ by $\bar{W}^{E}$ and $u^{E}$, respectively. The equilibrium promotion probability of a worker is thus $p^{E}\left(\bar{W}^{E}\right)=\left(1-F^{n}\left(\bar{W}^{E}-W^{E}\left(\bar{W}^{E}\right)\right)\right) / n<1 / n$. The following lemma proves useful:

Lemma $1 \partial\left(e^{E}+(n-1) a^{E}\right) / \partial \bar{W}>(<) 0$ if $\bar{W}<(>) W^{E}(\bar{W})$.

Proof: See Appendix.

With lemma 1 we can now compare the optimal output $W^{E}\left(\bar{W}^{E}\right)$ with the equilibrium output without external recruitment, $W^{* *}$. Suppose that $W^{E}\left(\bar{W}^{E}\right) \leqslant W^{* *}$. From Figure 1 we can see clearly that this is true only if $\bar{W}^{E} \geqslant \bar{W}^{\prime}$, where $\bar{W}^{\prime}$ is such that $W^{E}\left(\bar{W}^{\prime}\right)=$ $W^{* *}$. In that case $\bar{W}^{E} \geqslant \bar{W}^{\prime}>\bar{W}^{o}$. From Proposition 3 and Lemma 1 we know that $e^{E}+(n-1) a^{E}>e^{* *}+(n-1) a^{* *}$, which in turn implies that $v^{E}>v^{* *} \equiv v\left(e^{* *}+(n-1) a^{* *}\right)$. It follows that $\pi(\bar{W}, u)=n p^{E} W^{E}\left(\bar{W}^{E}\right)-v^{E}<W^{E}\left(\bar{W}^{E}\right)-v^{E} \leqslant W^{* *}-v^{* *}$. This contradicts the definition of $\bar{W}^{E}$, which is chosen to maximize $W^{E}-v^{E}$. ${ }^{15}$ We thus must have $W^{E}\left(\bar{W}^{E}\right)>W^{* *}$. That is, the output level under the optimal external recruitment policy is greater than that without external recruitment.

It is worthwhile to note that while external recruitment can improve the performance of the firm, it is not strong enough to totally eliminate the harm caused by negative activities. This can be easily seen by comparing (4) and (2), which show that $e^{*}>$ $e^{E}\left(\bar{W}^{E}\right)+(n-1) a^{E}\left(\bar{W}^{E}\right)$. As a result, $W^{*}>W^{E}\left(\bar{W}^{E}\right)$. We thus have

Proposition $4 W^{*}>W^{E}\left(\bar{W}^{E}\right)>W^{* *}$. That is, external recruitment can ameliorate, but cannot eliminate, the harm caused by sabotage.

Note that zero-profit condition implies that $u^{E}=W^{E}\left(\bar{W}^{E}\right) / n$. Similarly, zero-profit conditions for the cases with and without sabotage are $u^{*}=W^{*} / n$ and $u^{* *}=W^{* *} / n$,

\footnotetext{
${ }^{15}$ Note that $W^{* *}=W^{E}(-\infty)$ and $v^{* *}=\lim _{W \rightarrow-\infty} v^{E}$.
} 
respectively. Since $W^{E}\left(\bar{W}^{E}\right)>W^{* *}$, we know that $u^{E}>u^{* *}$. This means that in the presence of sabotage, the optimal wage gap is greater when the firm can recruit outsiders. The reason for this is straightforward. Since external recruitment can mitigate the problem of infight, the firm can afford to design a higher-powered incentive contract by setting a wider wage gap in order to induce higher productive effort. A simple corollary of Proposition 4 is thus:

Proposition 5 In case the firm makes zero profit, it follows that $u^{*}>u^{E}>u^{* *}$.

The result that $u^{*}>u^{* *}$ is exactly the main point made in Lazear (1989), which argues that in order to mitigate sabotage within a firm, it should narrow the wage gaps between hierarchies, despite the fact that it might simultaneously weaken their incentives to work.

The first order condition for $u$ under the case without external recruitment is

$$
\frac{\partial W^{* *}}{\partial u}=\left(\frac{\partial e^{* *}}{\partial u}+(n-1) \frac{\partial a^{* *}}{\partial u}\right) v^{\prime}(\cdot)
$$

The optimal choice of $u$ balances the trade-off between the benefit (left-hand side) of increasing $u$ and its cost (the right-hand side). On the other hand, the first-order condition under the case with external recruitment is

$$
\frac{\partial n p^{E}}{\partial u} W^{E}+n p^{E} \frac{\partial W^{E}}{\partial u}=\left(\frac{\partial e^{E}}{\partial u}+(n-1) \frac{\partial a^{E}}{\partial u}\right) v^{\prime}(\cdot) .
$$

The marginal cost of increasing the value of $u$ (right-hand side) is the same as in the case without external recruitment. There are, however, two sources of benefit in increasing $u$ now. As in the case without external recruitment, it influences the effort levels, and thus outputs, of the workers (the second term on the left-hand side). Moreover, since the change in effort will affect absolute output levels, it also changes the promotion chance of the inside workers (the first term on the left-hand side), as it changes the output level relative to outsiders. This is the term that is absent in the case without external recruitment, as the promotion probability is always $1 / n$ regardless of the value of $u$. Since $e$ increases the absolute value of output while $a$ decreases it, the only way to increase the probability of outperforming $\bar{W}$ is through the increase and $e$ (and perhaps 
reduction in $a$ ). Thus external recruitment shifts the workers' efforts from sabotage back to productive activities by forcing them to take into consideration the relative benefit of productive and negative effort in influencing their chance of promotion.

\section{Other Incentive Effects}

So far our discussion is focused on the function of external recruiting in reducing disruptive behavior in an organization. However, sometimes external recruitment can improve incentives even if negative activity is not a concern. This is especially so when the effort choice of the workers is discrete.

Suppose there are two workers in the firm vying for promotion. The workers can either exert high $(H)$ or low $(L)$ effort level. Assume that the output of the firm when they both exert high effort is so high that the firm prefers $(H, H)$ to $(L, L)$, after paying for the wages to the workers. As a result, the firm would like $(H, H)$ to be implemented. Also assume that the workers do not engage in negative activities. The disutility of high (low) effort level is $x(y)$, where $x>y>0$. Let $p_{i j}(i, j=H, L)$ be the probability that a worker is promoted when his effort level is $i$ and that of his opponent is $j$. The utility of being promoted is $u$, and is 0 otherwise. The expected utility of worker $i$ is thus $u_{i}(i, j ; u)=p_{i j} u-x$ if $i=H$ and is $p_{i j} u-y$ if $i=L$. The normal form expression of the game between the two workers is given in Table 1, where player 1 (2) is row (column) player.

\begin{tabular}{|c|c|c|}
\hline & $H$ & $L$ \\
\hline$H$ & $p_{H H} u-x, p_{H H} u-x$ & $p_{H L} u-x, p_{L H} u-y$ \\
\hline$L$ & $p_{L H} u-y, p_{H L} u-x$ & $p_{L L} u-y, p_{L L} u-y$ \\
\hline
\end{tabular}

\section{Table 1 Payoff matrix of workers}

The key insight is that without external recruitment, each of the workers has a promotion chance of $1 / 2$ as long as they exert the same effort level, regardless of high or low. 
(Specifically, without outside competition for promotion, the promotion chance of each worker is $1 / 2$ under both $(H, H)$ and $(L, L)$.) If the disutility of effort is substantial, then $(L, L)$ will be a Nash equilibrium. However, when there is outside competition, shirking of insiders will give the outsider a greater chance of being recruited. That means although external recruitment reduces the promotion chance of workers when they exert high effort levels, the decrement is not as large as when both shirk. If the reduction in promotion chance is substantial, then external recruitment shifts the Nash equilibrium of the game from $(L, L)$ to $(H, H) .{ }^{16}$

To give a concrete example, assume that $p_{H H}=1 / 2, p_{H L}=11 / 20, p_{L H}=9 / 20$, and $p_{L L}=1 / 2$. It is easy to see that as long as $x-y>u / 20$, then $(L, L)$ is the unique Nash equilibrium. ${ }^{17}$ Suppose by introducing external competition the firm can change promotion probabilities of the workers to $p_{H H}=1 / 3, p_{H L}=1 / 4, p_{L H}=1 / 12$, and $p_{L L}=1 / 10$. Then $(H, H)$ will be the only equilibrium if $\frac{3}{20} u>x-y \cdot{ }^{18}$ Numerically, if $u=40, x=10$ and $y=5$, then $(L, L)$ is the unique equilibrium when there is only internal promotion; and $(H, H)$ is the unique equilibrium when there is external recruitment. Thus external recruitment can change the payoff structure of the game so that the equilibrium shifts from the inefficient $(L, L)$ to the efficient one, $(H, H)$. The main specifications that drive this result are that (a) without external recruitment, the promotion chance of each worker is $1 / 2$ under either $(H, H)$ or $(L, L)$; and (b) with external recruitment, the promotion chance of each worker decreases, but the drop in promotion probability is greater for $(L, L)$ than $(H, H)$, as $1 / 2-1 / 10>1 / 2-1 / 3$.

Another function of external recruitment is concerned with collusion. As is suggested by Lazear (1995), promotion based on relative performance results in not only noncooperation and mutual sabotage, but also harmful cooperative behavior. In some cases, even if the firm designs the prize of promotion in such a way that exerting high level of

\footnotetext{
${ }^{16}$ Note that this result is impossible when the effort level is continuous. As can been seen from a slightly modified equation (1) that allows for external recruitment, the effort level always decreases when there is external recruitment. This means that our results in this section crucially depend on the discreteness assumption of effort levels. However, in reality this might not be an uncommon case.

${ }^{17}$ In fact exerting effort level $L$ is the dominant strategy for every worker.

${ }^{18}$ In this case, exerting effort level $H$ is the dominant strategy for every worker.
} 
effort is actually a Nash equilibrium, there is still possibility that the workers can collude to shirk and enjoy the gain from collusion. ${ }^{19}$ For example, in discussing the compensation practice of the banking-wiring room in the Hawthorne plant of Western Electric, Miller (1992) describes a game called "binging" played between workers that is actually used to punish the workers who produces too much; that is, it is a collusive device to prevents the workers from exerting high effort level. ${ }^{20}$ In this case, external recruitment is effective in reducing incentive to collude, because the presence of external competitor will reduce the promotion chance of all the inside workers if they collude to shirk. A simple example to explain this is as follows.

In Table 1 , let $P_{H H}=P_{L L}=1 / 2, u=24, x=4$, and $y=2$. Then there is a unique Nash equilibria of the game, $(H, H)$, where each receives a utility of 8 . However, although $(L, L)$ is not a Nash equilibrium, each worker can receive a higher utility of 10 under that strategy profile. Under this specification, Table 1 is actually a game of Prisoners' Dilemma, in which players are both better off when they cooperate to shirk, but non-cooperation (in which they both work hard) is the unique equilibrium. The workers thus have incentives to collude and coordinate on $(L, L)$. In our context, this can be achieved with the following side-contract: The workers agree that whoever wins the contest pays the loser an amount which equals half of the prize of winning, 24. In this case the workers' utilities is independent of the outcome of the tournament. Since payoff is now independent of outcomes, they all exert low effort level $L$. The utility of each is thus $1 / 2 \times 24-y=12-2=10$, which is exactly the collusive outcome. Note that this side-contract is verifiable and legal, and is thus enforceable. ${ }^{21}$ Again, we assume that the output of the firm when every worker exerts high effort level is so

\footnotetext{
${ }^{19}$ This is exactly the same kind of collusive behavior that occurs in competitive bidding.

${ }^{20}$ See also the discussion in Gibbons and Waldman (1999), Section IV.B.

${ }^{21}$ In a more complicated context, the enforcement of collusive behavior (and, more generally, sidecontract) might be a difficult problem. This area of study is still on the frontier of research with no consensus yet (See, for example, Tirole, 1992 and Felli and Villas-Boas, 1998). For our purpose, an easy way to sustain $(L, L)$ as a collusive result is to imbed the model in a repeated game context. In that case, a trigger strategy in the "relational contract" (Bull, 1987; Levine, 1993) can be used to sustain the collusive outcome among players.
} 
desirable that it wants to implement $(H, H)$. Thus collusion between the workers is harmful from the firm's perspective. By introducing external competition the firm can sometimes eliminate incentives of the workers to collude. For example, suppose that with external recruitment, promotion probability of inside workers is 0 when they all exert low level of effort, and is only slightly lower than $1 / 2$ when they exert high levels of effort. Then not only is $(H, H)$ still the unique equilibrium, but also the workers now do not have incentives to collude towards $(L, L)$, because the utility of each worker under this outcome is negative, and is thus Pareto-dominated by $(H, H)$. The reason for this result is, again, that shirking is more costly for the workers in the presence of external competition than without. When only insiders compete for promotion, reducing effort will not decrease the promotion probability of a worker, as long as all the other workers follow suit. When there is outside competition, even if every inside worker can collude to shirk, it only treats the outsider to a free lunch. Sometimes the loss of promotion chance is so large that the workers have no choice but to exert high effort level. As a result, external recruitment recovers $(H, H)$ not only as the unique Nash equilibrium, but also a Pareto-dominant outcome which is immune to collusion.

\section{Conclusion}

In this paper we show that, contrary to the common belief that external recruitment trades off the need for the outside talent with incentives of inside workers, external recruitment can unconditionally improve the performance of a firm. This is because external excruitment, by reducing the marginal return of sabotage by more than that of productive activities, can force the workers to substitute the former for the latter. As a result, the output of the firm increases. We go on to show that, even if sabotage is not a concern of the firm, external recruitment can still be a valuable practice in recovering incentives. For a firm stuck in low-effort equilibrium, the introduction of external competition might be able to force the workers to pay a higher price for shirking,

by so much so that it shifts the low effort equilibrium to a high effort one. For example, in 
an academic department, the junior faculty will probably work harder (in either teaching or research) when the department practices senior recruiting, than when they are sure that a senior position will be filled by one among them.

In some cases the game of promotion tournament might be characterized by a Prisoner's Dilemma, in which the equilibrium (with high effort level) is Pareto-dominated by a non-equilibrium outcome (with low effort level) for the players. In that case the workers will have incentives to collude and coordinate on the latter outcome, which gives them higher utility. The firm can break this collusion by introducing external competition. The reason for this is exactly the same: without external competition, the workers pay no price when they both shirk. When there is external recruitment, they are giving free-rides to outsiders if they collude to shirk.

By investigating the incentive aspect of external recruitment, this paper adds to the so far relatively scant literature regarding strategic approach to recruitment practice. As future research, it greatly enhances our understanding of the tournament aspect of promotion if we can combine the incentive and the traditional adverse selection considerations of external recruitment in an integrated model. 


\section{Appendix}

(i) Proof of Proposition 2:

Differentiating (4) and (5) with respect to $\bar{W}$, and solving for $\partial e / \partial \bar{W}$ and $\partial a / \partial \bar{W}$ we have $^{22}$

$$
\begin{gathered}
\frac{\partial e}{\partial \bar{W}}=(n-1) \frac{u t f^{\prime} F^{n-1}\left[v^{\prime \prime}-u g^{\prime \prime} \int_{\bar{W}-W^{E}}^{\infty} f^{2}(\varepsilon) F(\varepsilon)^{n-2} d \varepsilon\right]+u g^{\prime} f^{2} F^{n-2} v^{\prime \prime}}{\Delta}, \\
\frac{\partial a}{\partial \bar{W}}=\frac{u F^{n-2} v^{\prime \prime}\left\{g^{\prime} f^{2}+t f^{\prime} F\right\}}{-\Delta} ;
\end{gathered}
$$

where $\Delta=-(n-1)\left[u t^{2} f^{\prime} F^{n-1}+v^{\prime \prime}\right]\left[u g^{\prime \prime} \int_{W}^{\infty}-W^{E} f^{2}(\varepsilon) F(\varepsilon)^{n-2} d \varepsilon+u g^{\prime 2} f^{2} F^{n-2}-v^{\prime \prime}\right]+$ $(n-1)\left[u t g^{\prime} f^{\prime} F^{n-1}+v^{\prime \prime}\right]\left[u t g^{\prime} f^{2} F^{n-2}-v^{\prime \prime}\right]$, which is positive by the second-order condition. Since $f^{\prime}(x)>0$ if and only if $x<0$, we know from (A1) and (A2) that $\partial e / \partial \bar{W}>0$ and $\partial a / \partial \bar{W}<0$ if $\bar{W}<W^{E}(\bar{W})$.

(ii) Proof of Proposition 3:

The first order condition for $\bar{W}^{E}$ is

$$
\begin{aligned}
\frac{\partial W^{E}}{\partial \bar{W}} & =t \frac{\partial e^{E}}{\partial \bar{W}}-(n-1) g^{\prime} \frac{\partial a^{E}}{\partial \bar{W}} \\
& =(n-1) \Delta^{-1}\left\{\begin{array}{c}
\left(t v^{\prime \prime}-t u g^{\prime \prime} \int_{\bar{W}-W^{E}}^{\infty} f(\varepsilon)^{2} F(\varepsilon)^{n-2} d \varepsilon+g^{\prime} v^{\prime \prime}\right) u t F^{n-1} f^{\prime} \\
+\left(t+g^{\prime}\right) u F^{n-2} v^{\prime \prime} f^{2} g^{\prime}
\end{array}\right\}=0 .
\end{aligned}
$$

The second term in the brace is positive, and the term in the parenthesis of the first term is also positive. Consequently, $f^{\prime}\left(\bar{W}^{E}-W^{E}\left(\bar{W}^{E}\right)\right)$ must be negative. Since $f^{\prime}(x)>0$ if and only if $x<0$, this implies that $W^{E}\left(\bar{W}^{E}\right)>\bar{W}^{E}$.

(iii) Proof of Lemma 1:

From (A1) and (A2) we know that

$$
\frac{\partial\left(e^{E}+(n-1) a^{E}\right)}{\partial \bar{W}}=-\frac{u^{2} t F^{n-2} f^{\prime} g^{\prime \prime} \int_{\bar{W}-W^{E}}^{\infty} f^{2}(\varepsilon) F(\varepsilon)^{n-2} d \varepsilon}{\Delta} .
$$

\footnotetext{
${ }^{22}$ For brevity we have omitted the variables in functions $v(e), F\left(\bar{W}-W^{E}\right)$, and $f\left(\bar{W}-W^{E}\right)$.
} 
Obviously, the expression above is positive (negative) if $f^{\prime}\left(\bar{W}-W^{E}(\bar{W})\right)>(<) 0$, which in turns implies $\bar{W}<(>) W^{E}(\bar{W})$. 


\section{References}

[1] Baker, G., M. Gibbons and B. Holmstrom (1994), "The Internal Economics of the Firm: Evidence from Personnel Data, Quarterly Journal of Economics, 109, 881-919.

[2] Baron, J. N. and D. M. Kreps (1999), Strategic Human Resources: Frameworks for General Managers, John Wiley, New York, NY.

[3] Batt, R. (1996), "From Bureaucracy to Enterprise? The Changing Jobs and Careers of Managers in the Telecommunication Service," in Broken Ladder: Managerial Careers in the New Economy, P. Osterman ed., Oxford University Press, New York, NY.

[4] Bognanno, M. L. (1999), "Corporate Tournament," Journal of Labor Economics, 19, 290-315.

[5] Bull, C. (1987), "The Existence of Self-Enforcing Implicit Contracts," Quarterly Journal of Economics, 147-60.

[6] Chan, W. (1996), "External Recruitment versus Internal Promotion" Journal of Labor Economics, 14, 555-70.

[7] Chen, K. -P. (2003), "Sabotage in Promotion Tournaments," Journal of Law, Economics and Organization, 19, 119-40.

[8] Doeringer, P. and M. Piore (1985), Internal Labor Markets and Manpower Analysis, M. E. Sharpe, UK.

[9] DeVaro, J. (2002), "Promotion Tournament in Real Firms," mimeo, Cornell University.

[10] Eriksson, T. (1999), "Executive Compensation and Tournament Theory: Empirical Test on Danish Data," Journal of Labor Economics, 17, 262-80. 
[11] Felli, L. and M. Villas-Boas (2000), "Renegotiation and Collusion in Organization," Journal of Economics and Management Strategy, 9, 453-83..

[12] Friebel, G. and M. Raith (2001), "Abuse of Authority and Hierarchical Communication," forthcoming in RAND Journal of Economics.

[13] Gibbons, R. and M. Waldman (1999), "Careers in Organizations: Theory and Evidence," in O. Ashenfelter and D. Card ed., Handbook of Labor Economics Vol. 3, North Holland, Netherlands.

[14] Green J. and N. Stokey (1983), "A comparison of Tournaments and Contests," Journal of Political Economy, 91, 349-64.

[15] Hvide, H. K. (2002), "Tournament and Risk Taking,", Journal of Labor Economics, 20, 877-98.

[16] Kanter, R. (1989), When Giants Learn to Dance, Simon \& Schuster, New York, NY.

[17] Lazear, E. P. (1989), "Pay Equality and Industrial Politics," Journal of Political Economy, 97, 561-80.

[18] (1995), Personnel Economics, MIT Press, Cambridge, MA.

[19] — and S. Rosen. (1981), "Rank-Order Tournament as Optimum Labor Contract," Journal of Political Economy, 89, 841-64.

[20] Levin, J. (2003), "Relational Incentive Contracts," American Economic Review, 93, 835-57.

[21] Miller, G. (1992), Managerial Dilemma: The Political Economy of Hierarchy, Cambridge University Press, New York, NY.

[22] Müller, H. and K. Wärneryd (2001), "Inside versus Outside Ownership: A Political Theory of the Firm," RAND Journal of Economics, 32, 527-41. 
[23] Osterman, P. (1999), Securing Prosperity: The American Labor Market: How it has Changed and What to do About it, Princeton University Press, Princeton, NJ.

[24] Rosen, S. (1986), "Prizes and Incentives in Elimination of Tournaments," American Economic Review, 76, 701-15.

[25] Tirole, J. (1992), "Collusion and the Theory of Organizations," in J.-J. Laffont ed., Advances in Economic Theory Vol.2, Cambridge University Press, Cambridge, UK.

[26] Zabojnik, J. and D. Bernhardt (2001), "Corporate Tournaments, Human Capital Acquisition, and the Firm Size-Wage Relation," Review of Economic Studies, 68, 693-716. 